\title{
A comparison of the TRCII and latex-particle tests for the titration of FR-antigen
}

\author{
C. L. AROCHA-PIÑNANG ${ }^{1}$ \\ From the Department of Haematology, St Thomas's Hospital Medical School, London
}

SYNOPSIS The great convenience of a method using a suspension of antibody-coated latex particles for the titration of fibrinogen-related antigens over the tanned red cell baemaglutination immunoassay (TRCHII test) of Merskey, Lalezari, and Johnson (1969) has been demonstrated. The usefulness of Ca-Ancrod for the defibrination of heparinized plasma is presented here.

There is increasing interest in methods for titrating fibrinogen-related antigen (FR-antigen, 'fibrinogen/ fibrin degradation products', 'fibrinogen split products'). A suspension of antibody-coated latex particles, becoming commercially available, provides a very simple method. In the following experiments this latex method has been compared with the modified tanned red cell haemagglutination inhibition immunoassay (TRCHII test) of Merskey, Lalezeri, and Johnston (1969). Titres were obtained in parallel from various normal and abnormal sera, and the effect of the defibrination of plasma samples with thrombin, ancrod (Arvin and), reptilase, and the effect of heparin were investigated.

\section{Materials}

\section{BUFFERS}

The citrate-saline buffer, $p \mathrm{H} 6.4$, for the TRCHII test was prepared as described by Merskey et al (1969). A glycine buffer was also prepared by dissolving glycine to a concentration of $0 \cdot 1 \mathrm{M}$ in $1 \%$ $\mathrm{NaCl}$ containing $0.1 \%$ sodium azide; the $p \mathrm{H}$ was adjusted to $8 \cdot 2$ with $\mathrm{NaOH}, 0 \cdot 2 \mathrm{M}$. Both buffers were stored at $4^{\circ} \mathrm{C}$.

LATEX PARTICLES COATED WITH ANTIFIBRINOGEN ANTIBODY

A suspension of latex particles described as being coated with a mixture of anti-D and anti-E antibodies (where $\mathrm{D}$ and $\mathrm{E}$ are late fibrinogen fragments) was kindly supplied by Wellcome Reagents Limited, Wellcome Research Laboratories. The suspension was stored at $4^{\circ} \mathrm{C}$.

\section{TANNED RED CELLS}

Tanned red cells were prepared as described by 'Permanent address: I.V.I.C., Apartado 1827, Caracas Venezuela.
Merskey et al (1969) and were stored at $4^{\circ} \mathrm{C}$; a batch could be used for about a month.

\section{ANTIFIBRINOGEN ANTISERUM}

A rabbit antiserum to human fibrinogen (Hyland) was diluted in citrate buffer as required.

FIBRINOGEN STANDARD

A freeze-dried fibrinogen standard supplied by Wellcome Research Laboratories was reconstituted to obtain a stock solution at $10 \mu \mathrm{g} / \mathrm{ml}$.

\section{DEFIBRINATING REAGENTS}

Calcium-thrombin (Ca-thrombin) was prepared by reconstituting bovine thrombin (Parke, Davis) in citrate buffer to a concentration of $1000 \mathrm{u} / \mathrm{ml}$ and stored frozen in aliquots containing $100 \mathrm{u}$. For use, an aliquot was thawed and diluted with about $20 \mathrm{ml}$ of $\mathrm{CaCl}_{2}$ solution 0.025 - $\mathrm{M}$ and adjusted to obtain a clotting time of 12 to $15 \mathrm{sec}$ with normal citrated plasma (equal volumes of buffer, plasma, and Ca-thrombin solution).

Calcium-ancrod (Ca-ancrod) was prepared by diluting 1 ampoule $(1.1 \mathrm{ml})$ of ancrod (Arvin, Twyford Laboratories Limited), $67 \mathrm{u} / \mathrm{ml}$, with about $10 \mathrm{ml}$ of $\mathrm{CaCl}_{2}$ solution $0.025-\mathrm{M}$, adjusting the clotting time as for the Ca-thrombin solution.

Calcium-reptilase (Ca-reptilase) was prepared by reconstituting an ampoule of Reptilase- $\mathrm{R}$ in $\mathrm{CaCl}_{2}$ solution $0.025-\mathrm{M}$ to $1.0 \mathrm{ml}$ as recommended by the manufacturers. To obtain more concentrated solutions, ampoules were sometimes reconstituted in less than this volume; from these latter, solutions were adjusted with $\mathrm{CaCl}_{2}$ solution to yield clotting times of 12 to $15 \mathrm{sec}$ with normal plasma as for Ca-thrombin.

All these solutions were freshly prepared for each day's work. 
HEPAR I N

Mucous heparin $1000 \mathrm{IU} / \mathrm{ml}$ (batch 315, Weddel Pharmaceuticals Limited) was diluted in physiological saline and added to plasma (in the proportion of 1 volume of solution to 9 volumes of plasma) to obtain a final concentration of $4 \mathrm{IU} / \mathrm{ml}$ of plasma.

\section{PROTAMINE SULPHATE}

Using the batch of heparin defined above, it was sound by titration that 100 IU was neutralized by $1.25 \mathrm{mg}$ of a certain batch of protamine sulphate solution (Evans Medical). (Method: thrombin clotting time in normal citrated plasma.) The appropriate quantity of this protamine sulphate solution was added to the $\mathrm{Ca}$-thrombin reagent to neutralize the heparin added to the plasma, as described above, in the relevant experiments.

\section{Methods}

DEFIBRINATING PLASMA SAMPLES

Equal volumes of solutions of trisodium citrate dihydrate, $6.4 \%$, and aminocaproic acid solution, $20 \%$, were mixed. Blood was added to this mixture in the proportion of $9 \mathrm{vol}$ to $1 \mathrm{vol}$ and centrifuged at $3000 \mathrm{rpm}$ for $10 \mathrm{~min}$ at room temperature to obtain citrated plasma. Aliquots of plasma (usually $\mathbf{0 . 3}$ or $0.5 \mathrm{ml}$ ) were mixed with equal volumes of the defibrinating reagents and incubated for $30 \mathrm{~min}$ at $37^{\circ} \mathrm{C}$. The clots were removed with applicator sticks and the supernatant sera centrifuged for $5 \mathrm{~min}$ at $3000 \mathrm{rpm}$. Sera were prepared either from fresh plasma or from plasma samples which had been stored for up to two weeks at $-20^{\circ} \mathrm{C}$.

\section{DILUTING TEST MATERIALS}

For testing the fibrinogen standard, serial two-fold dilutions were prepared from the $10 \mu \mathrm{g} / \mathrm{ml}$ solution; when testing plasmas, two-fold serial dilutions were made from undiluted plasma. Dilutions were made in glycine buffer using a $\mathbf{0 . 1} \mathrm{ml}$-graduated Pasteur pipette, in the wells of a WHO agglutination tray.

\section{PERFORMANCE OF THE TEST}

TRCHII test

For the TRCHII test, tanned red cells were resuspended every day in citrate saline buffer and filtered through cotton gauze before use. The serial dilutions were prepared in the WHO tray and an equal volume of diluted antiserum, 1 in 500 to 1 in 800 , was added to each well, the tray mixed by shaking and allowed to stand $20 \mathrm{~min}$ at room temperature with occasion

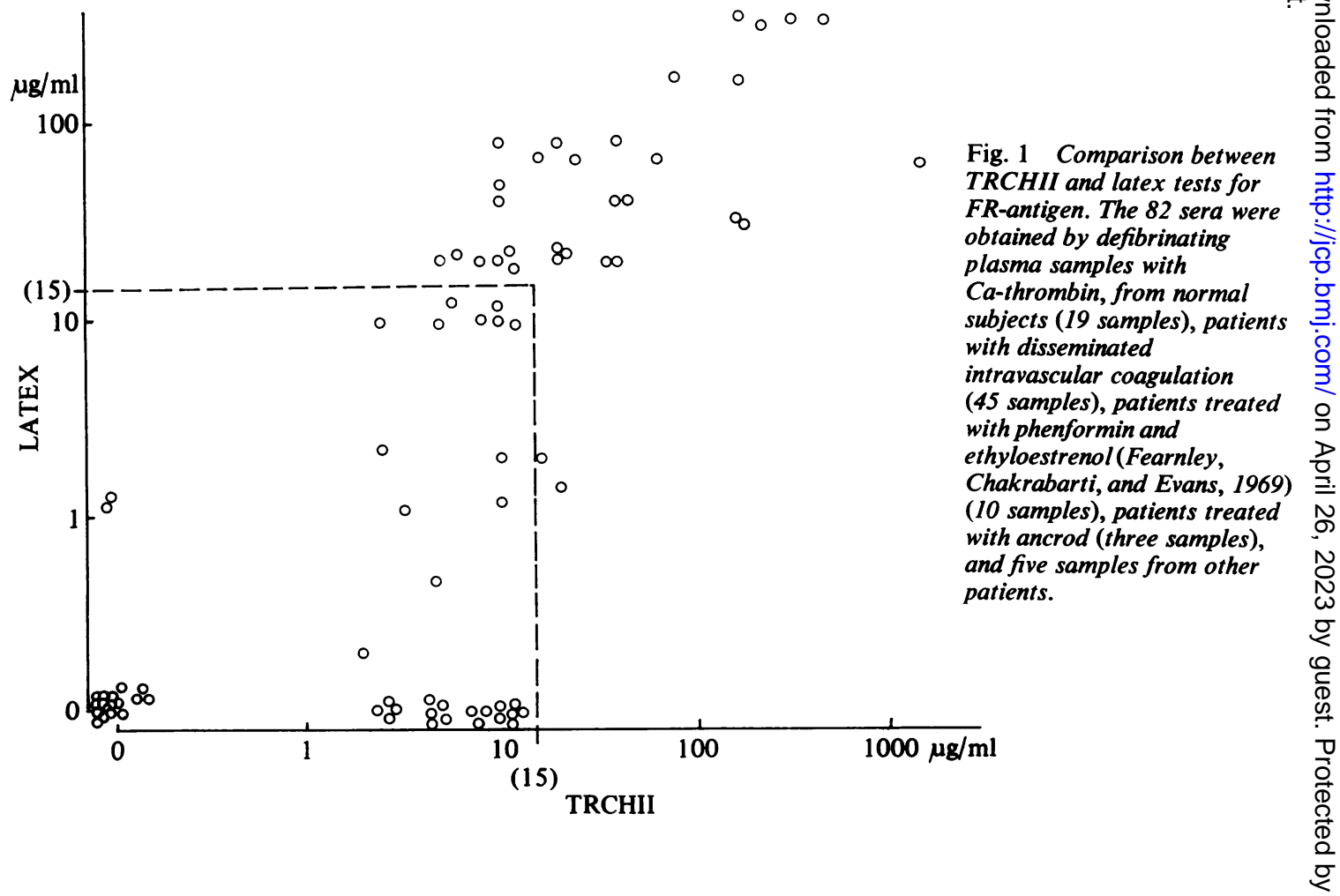


further shaking. The cell suspension (about $4 \%$ ) was then added to each well; the quantity was usually one drop, but two drops were used when the cells were aging. The plate was then either shaken continuously for $15 \mathrm{~min}$ at room temperature and the end points read, or alternatively was initially mixed and covered, andallowed to stand for one hour at room temperature with further occasional shaking until read. At fortnightly intervals, red cells from a day's working batch were tested with several dilutions of the antifibrinogen antiserum to ensure the choice of the correct dilution as the cells became older.

\section{Latex test}

For the latex test, 1 drop of each dilution of test serum was placed on a grease-free glass slide or plate. The latex suspension was shaken vigorously for a few min and one drop added to each drop of diluted serum. The drops were stirred together with a wooden applicator stick and in each case spread over a circular area of diameter about $2 \mathrm{~cm}$. The glass was rocked gently to and fro against a distant dark background with a bright light source behind the observer. The end point was the highest dilution to show naked-eye agglutination within 2 minutes.

\section{Results}

\section{SENSITIVITY AND NORMAL VALUES FOR THE}

METHODS

The sensitivities of the methods were in the ranges of 0.65 to $4.0 \mu \mathrm{g} / \mathrm{ml}$ for the TRCHII test and 1.25 to $5.0 \mu \mathrm{g} / \mathrm{ml}$ for the latex test. Sera from normal plasmas gave titres up to 1 in 4 in both tests, corresponding to upper limits of $8 \mu \mathrm{g} / \mathrm{ml}$ for the TRCHII test and $16 \mu \mathrm{g} / \mathrm{ml}$ for the latex test.

\section{CORRESPONDENCE BETWEEN THE METHODS}

Figure 1 shows the results of 82 titrations of various sera carried out in parallel by the two methods. There is an obvious correlation but considerable experimental variation. Taking the results from both methods together it appears that values up to 16 $\mu \mathrm{g} / \mathrm{ml}$ cannot be distinguished from zero.

\section{EFFECT OF DEFIBRINATION WITH ANCROD}

One hundred and four plasma samples were defibrinated in parallel with $\mathrm{Ca}$-thrombin and $\mathrm{Ca}$ ancrod. The TRCHII test gave rather higher values on the ancrod-defibrinated samples (Fig. 2) but no systematic difference could be detected in the results of 63 tests by the latex method (Fig. 3).

EFFECT OF DEFIBRINATION WITH REPTILASE When the Reptilase reagent was reconstituted to the recommended volume (as for measuring the Rep-

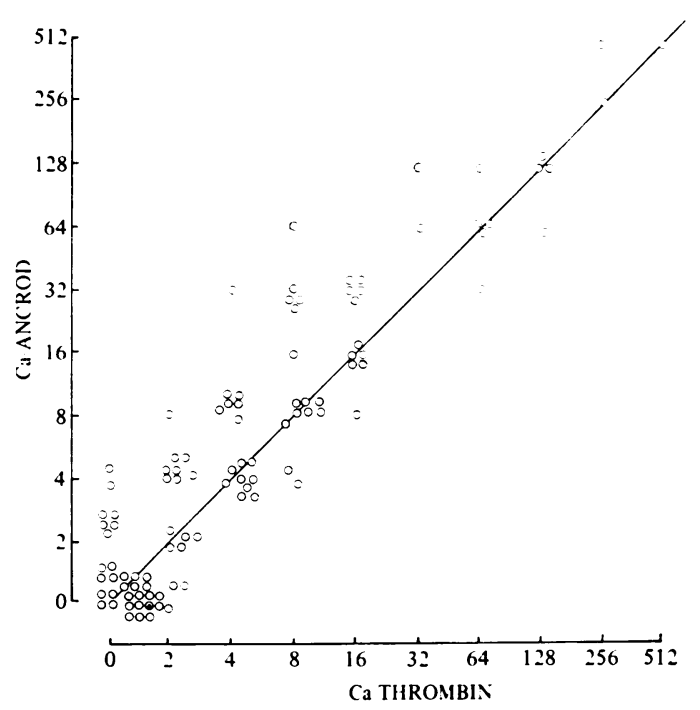

Fig. 2 TRCHII-test titres in 104 plasma samples defibrinated in parallel with Ca-thrombin and with Ca-ancrod (Cf Fig. 3).

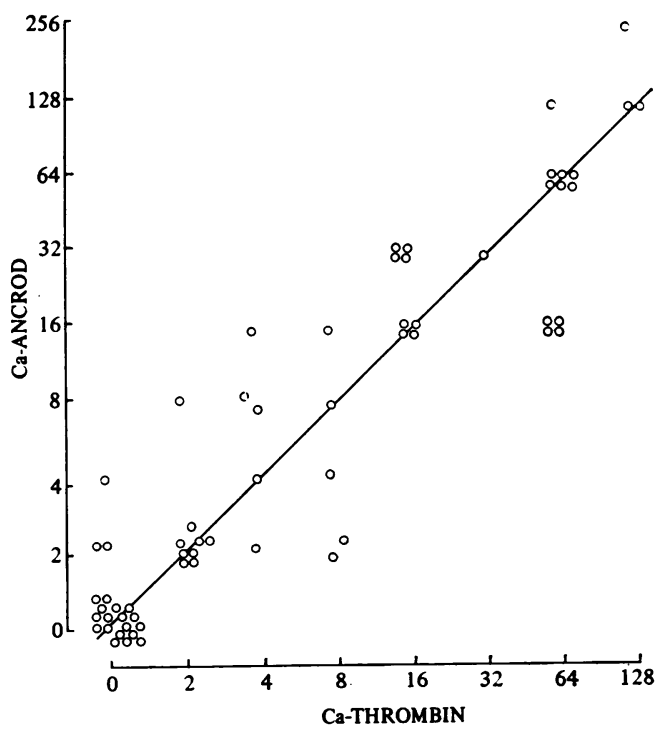

Fig. 3 Latex-test titres in 63 plasma samples defibrinated in parallel with Ca-thrombin and with Ca-ancrod (Cf Fig. 2). 


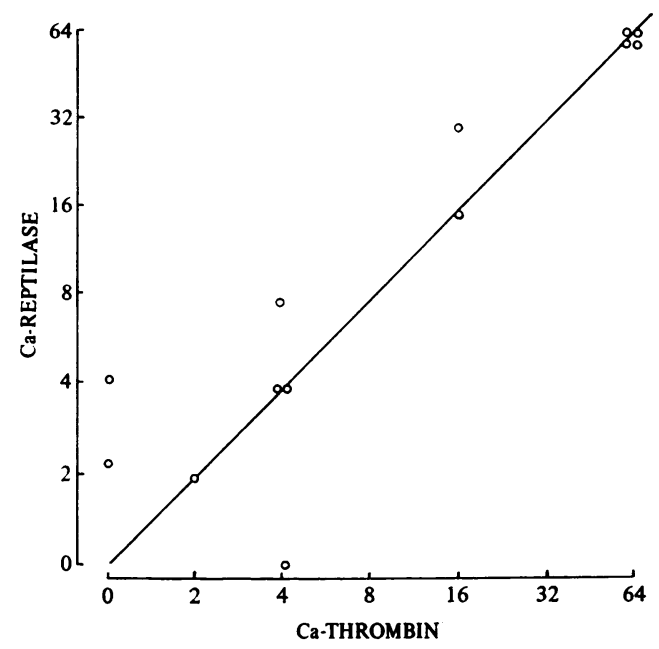

Fig. 4 Latex-test titres in 13 miscellaneous plasma samples defibrinated in parallel with Ca-thrombin and with Ca-Reptilase.

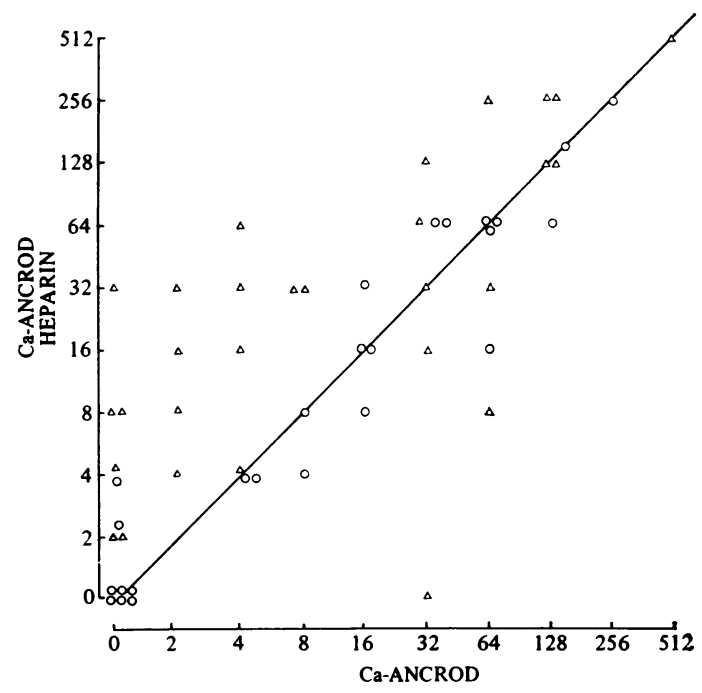

Fig. 5 Effect of heparin on TRCHII and latex tests. Miscellaneous plasma samples defibrinated with $\mathrm{Ca}$ ancrod: heparinized vs. unheparinized aliquots; $\triangle 29$ titrations by TRCHII test, $\bigcirc 25$ titrations by latex test . tilase-time), the TRCHI test gave much higher titres than parallel samples defibrinated with Ca-thrombin. When the Reptilase concentration was raised (as described above) to give clotting times corresponding to those with the Ca-thrombin reagent, the TRCHII test showed haemolysis of the red cells up to a serum titre of 1 in 128 . With this higher concentration of Reptilase, the latex test showed minimally higher titres with Ca-Reptilase- defibrination than with Ca-thrombin defibrination in 13 samples tested in parallel (Fig. 4). However, because of the $\bar{O}$ haemolysis in the TRCHII test, this method of defibrination was not further examined.

\section{EFFECT OF HEPARIN}

It was important to know if satisfactory titrations could be carried out on the blood of heparinized patients; a plasma concentration of $4 \mathrm{IU} / \mathrm{ml}$ was adopted for testing, since this is approximately the concentration employed during open-heart surgery on extracorporeal circulation (Kendall and Lowen- $\vec{c}$ stein, 1962). Since ancrod clots fibrinogen in the presence of heparin (Chan, Rizza, and Henderson, 1965), such samples could be defibrinated with the Ca-ancrod reagent. It was therefore necessary to investigate the effect of heparin on the titration $\overrightarrow{0}$ itself. Various plasma samples were therefof $N$ heparinized at $4 \mathrm{IU} / \mathrm{ml}$, as described, defibrinate with $\mathrm{Ca}$-ancrod, and tested in parallel againf unheparinized aliquots similarly defibrinated. Twenty-nine parallel titrations were made by the TRCHII method and 25 with the latex method. The results (Fig. 5) showed that at lower titres there was clear evidence of haemagglutination inhibition by heparin but that the effect appeared to have been diluted out at higher titres. In 14 parallel titrations with the latex method there was no evidence of perturbation by heparin.

An attempt was then made to employ the TRCHII method after neutralization of the heparin with protamine sulphate. Various plasma samples were therefore divided into two portions: one portion was defibrinated as usual with Ca-thrombin and the other $ᄋ$ portion heparinized. The heparinized portion was further subdivided, one part being defibrinated as before with $\mathrm{Ca}$-ancrod and the other with a $\mathrm{Ca}-\frac{\bar{N}}{\mathrm{~N}}$ thrombin solution containing the appropriate $ᄋ$ quantity of protamine sulphate. The three resulting $N$ sera were each tested by both methods. The results are shown in Fig. 6, where all the titres from the heparinized sera are plotted against those obtained from the unheparinized sera defibrinated with $\mathrm{Ca}-\frac{\mathrm{C}}{\Phi}$ thrombin. With the TRCHII test, both the sera 只 derived from the heparinized plasma gave higher titres of haemagglutination inhibition than the corresponding unheparinized sera, but again the 


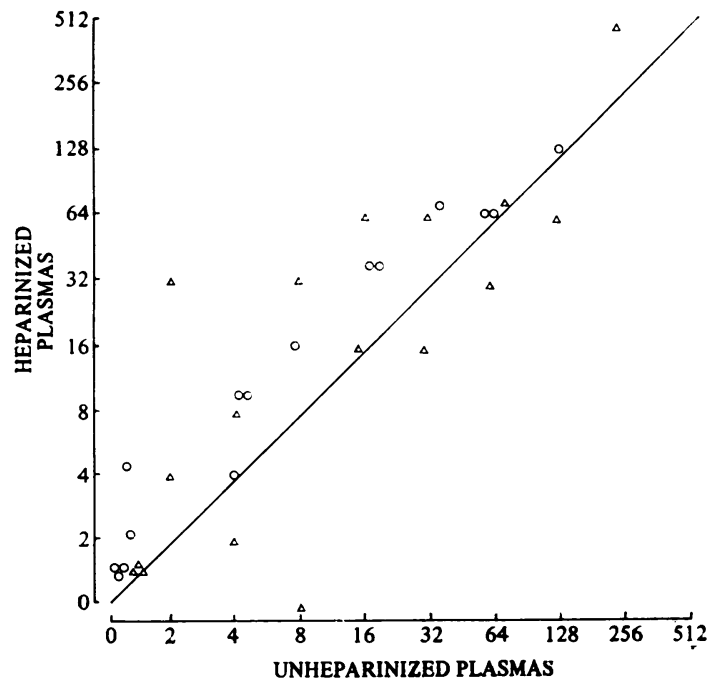

Fig. 6.

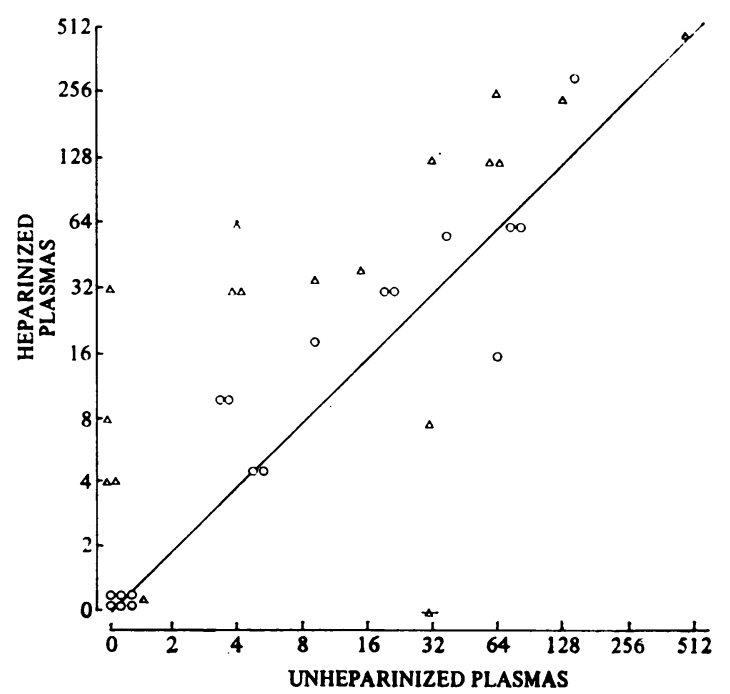

Fig. 7.

Figs. 6 and 7 Comparison of titres on sera from unheparinized plasmas defibrinated with Ca-thrombin with titres from the same plasmas heparinized and defibrinated either with Ca-ancrod or with Ca-thrombin and protamine sulphate, in TRCHII and latex tests (Fig. 6). Heparinized plasmas defibrinated with Ca-ancrod: $\triangle$ TRCHII test (2I samples); $\bigcirc$ latex test (15 samples) (Fig. 7). Heparinized plasmas defibrinated with Ca-thrombin and protamine sulphate: $\triangle$ TRCHII test (19 samples); O latex test (18 samples)

latex method gave reasonable correspondence between the parallel sera.

\section{Discussion}

Merskey, Kleiner, and Johnson (1966), Traill (1969), and Thomas, Niewiarowski, Myers, Bloch, and Colman (1970) have used latex particles coated with anti-fibrinogen antiserum, intended for the detection of a critical level of plasma fibrinogen concentration (the Hyland Fi-test), to detect FR-antigen. They found this test more sensitive to early products (threshold 1-2.5 $\mu \mathrm{g} / \mathrm{ml}$ ). Allington (1970) employed latex particles coated with fibrinogen; and Mellinger (1970) prepared a latex suspension similar to that used in the present study, which he found equally sensitive to early and late (D) products (threshold $17.0 \mu \mathrm{g} / \mathrm{ml}$ ). The relative sensitivity of the present reagent to various fibrinogen-derived fragments has not been personally investigated.

The great convenience of the latex method is selfevident. The correspondence of results with those obtained by the TRCHII test are confirmed; and the usefulness of the method is extended by the present finding that satisfactory test sera can be prepared from heparinized blood samples after defibrination of the plasma with Ca-ancrod.

The latex reagent was supplied by courtesy of
Wellcome Research Laboratories, ancrod by Twyford Laboratories Limited, and Reptilase by Paines and Byrne Limited, Pabyrn Laboratories, Perivale, Greenford, Middlesex; I would like to thank Dr G. I. C. Ingram for his help in preparing this paper, and Instituto Venezolano de Investigaciones Cientificas for financial support.

\section{References}

Allington, M. J. (1970). Detection of fibrinogen degradation products by a latex clumping method. Scand. J. Haemat., Suppl., 13, 115-119.

Chan, K. E., Rizza, C. R., and Henderson, M. P. (1965). A study of the coagulant properties of Malayan pit-viper venom. Brit. J. Haemat., 11, 646-653.

Fearnley, G. R., Chakrabarti, R., and Evans, J. F. (1969). Fibrinolytic and defibrinating effect of phenformin plus ethyloestrenol in vivo. Lancet, 1, 910-914.

Kendall, A. G., and Lowenstein, L. (1962). Alterations in blood coagulation and hemostasis during extracorporeal calculation. The Canad. med. Ass. J., 87, 962.

Melliger, E. J. (1970). Detection of fibrinogen degradation products by use of antibody coated latex particles: the possibilities and limits of the method. Thrombos. Diathes. haemorrh. (Stuttg.), 23, 211-227.

Merskey, C., Kleiner, G. J., and Johnson, A. J. (1966). Quantitative estimation of split products of fibrinogen in human serum: relation to diagnosis and treatment. Blood, 28, 1-18.

Merskey, C., Lalezari, P., and Johnson, A. J. (1969). A rapid, simple, sensitive method for measuring fibrinolytic split products in human serum. Proc. Soc. exp. Biol. (N.Y.), 131, 871-875.

Thomas, D. P., Niewiarowski, S., Myers, A. R., Bloch, K. J., and Colman, R. W. (1970). A comparative study of four methods for detecting fibrinogen degradation products in patients with various diseases. New Engl. J. Med., 283, 663-668.

Traill, M. A. (1969). Latex tests in the differentiation of hypercoagulability states leading to secondary fibrinolysis, and primary fibrinolysis. Lab. Pract., 18, 425-426. 